\title{
Buckling of Hybrid Composite Carbon/Epoxy/Aluminum Plates with Cutouts
}

\author{
Belkacem Achour \\ College of Engineering \\ University of Hail \\ Hail, Saudi Arabia \\ b.achour@uoh.edu.sa
}

\author{
Djamel Ouinas \\ Faculty of Engineering \\ University of Mostaganem \\ Mostaganem, Algeria \\ douinas@netcourrier.com
}

\author{
Mabrouk Touahmia \\ College of Engineering \\ University of Hail \\ Hail, Saudi Arabia \\ m.touahmia@uoh.edu.sa
}

\author{
Mustapha Boukendakdji \\ College of Engineering \\ University of Hail \\ Hail, Saudi Arabia \\ m.boukendakdji@uoh.edu.sa
}

\begin{abstract}
Structural instability becomes an important concern in the composite plate safe and reliable design. In this research, a resistance analysis is carried out on plates made of hybrid composite material with and without elliptical cutouts using the finite element method. The carbon/epoxy/aluminum laminated plates are arranged in the following ordered manner $[\mathrm{Al} /(\boldsymbol{\theta} /-$ 0)/Al]. The hybrid plate resistance to buckling submitted to uniaxial compression is highlighted. Results indicate that given a structural geometry, boundary and loading condition and stacking sequence, the buckling resistance of such plates is strongly influenced by the ply orientation, the anisotropy ratio, and the cutout presence, position and size. The critical load reduction is found to decrease linearly with the decrease of the geometric ratio $a / b$. When $b=8 a$, the reduction factor $N^{*}$ increased from $1.8 \%$ to $7 \%$ when $\varphi=90^{\circ}$ and $\varphi=0^{\circ}$ respectively regardless of the ply orientation. Maximum reduction of the buckling critical load is important when the elliptical cutout is located in the middle of the plate. Regardless of the declination of the elliptical cutout, maximum reduction of the critical buckling stress is obtained when the ratio $E_{2} / E_{1}=1$.
\end{abstract}

Keywords-elliptical cutout; buckling; hybride composite; finite element analysis

\section{INTRODUCTION}

Composite materials in the form of laminated plates or shells, have found a growing use in many industrial applications due to their high resistance to fatigue and corrosion and therefore their satisfactory durability. In addition, the minimization of the structural mass in the aeronautical industry leads directly to reducing the aircraft fuel consumption which constitutes an important technological advancement. These shell structures however present cutouts that serve as access pathways, windows which require some kind of reinforcement to overcome the local deformations and stresses around them. In addition, these structures may be subjected to compressive loadings something that requires an understanding of their buckling response in order to determine effective designs [1]. Designing structures of this type needs tools to model their more and more sophisticated mechanical behavior and consideration of their specificities. Numerical methods and in particular the finite element methods are essential for sizing these complex composite structures. Analysis of laminated plate behavior always remains an open research problem, due to its complexity [2].

The structural instability becomes an important concern in the safe and reliable design of composite plates. Several studies of laminated plate stability have been concentrated on rectangular plates [3-6]. It is known that the rectangular plate resistance to buckling depends on the boundary conditions, the orientations of the plies and the geometrical ratios [7-10]. The widely used thin walled composite structures become unstable when subjected to mechanical or thermal loadings leading to buckling. Accordingly, their behaviors in buckling are significant factors in safe and reliable design [11]. To predict the buckling load and the deformation mode of a structure, linear analysis remains a valid evaluation technique [12]. In general, the laminated plate analysis is more complicated than the analysis of an isotropic and homogeneous material [10]. In [13] authors performed a buckling analysis of a laminated composite rectangular plate having a circular hole at the centre. Authors in [14] studied the influence of a cutout on the behavior to buckling of symmetrically crossed composite laminated rectangular plates having a polymer matrix (PMC) using the finite element method. Authors in [15] studied the effect of fiber orientation on the critical load of buckling of a symmetrical laminated composite plate having a crack emanating from a circular cutout. They indicated that the buckling critical load reaches its maximum values when the plies were oriented in an interval varying from $50^{\circ}$ to $90^{\circ}$. In [16], authors studied the effect of the presence of an elliptical notch on the buckling of laminated boron/epoxy plates arranged anti-symmetrically $[(\theta /-\theta]$. In this study the buckling of composite plates made of hybrid carbon/epoxy/ aluminum material with and without elliptical cutouts is analyzed using the finite element software ABAQUS 6.11. The effects of the cutout size, position, orientation with respect to $\mathrm{x}$-axis, the orientation of plies and the rigidity ratio $\mathrm{E}_{2} / \mathrm{E}_{1}$ on the buckling load have been examined.

\section{FINITE ELEMENT MODEL}

A thin square plate made of hybrid carbon/epoxy/aluminum composite material, with length and width $2 \mathrm{~h}=100 \mathrm{~mm}$ and $2 \mathrm{w}=100 \mathrm{~mm}$ respectively and having an elliptical cutout at the center is considered. Total thickness is $\mathrm{e}=1.162 \mathrm{~mm}$. Plate's 
lower edge is fixed and the displacement on the upper edge is assumed to be free along the y-axis. The plate is subjected to a uniaxial compression in the vertical direction under the load per unit length $\sigma=1 \mathrm{~N} / \mathrm{mm}$. To solve the problem numerically, the finite element tool ABAQUS 6.11 was used with 33328 S8R quadrilateral elements and 397 STRI65 elements with a refined mesh at the vicinity of the cutout. The plate was composed of eight plies, six of carbon/epoxy and two of aluminum alloy. Carbon/epoxy layer's thickness is $0.127 \mathrm{~mm}$ and the plies were symmetrically crossed in an orderly alternate manner according to an angle of $\theta$ and $-\theta$ respectively. Aluminum layers were outside the plate and each had $0.2 \mathrm{~mm}$ thickness. Several mesh sizes were used in the numerical calculation to examine the accuracy and the convergence of a test case chosen where the ratio of the elliptical cutout is $b / a=3$, and the orientation of the layers is $[-45 / 45]_{3}$. A uniform loading was applied taking into account the boundary conditions. The classical model theory of laminates was implemented using the shell elements S4R, S8R of ABAQUS with the composite layup option. The linear and quadratic elements with reduced integration S4R and S8R are generally well suited for the calculation of semi-thick or thin shells. Mechanical properties of the hybrid composite plate are given in Table I.

TABLE I. MECHANICAL PROPERTIES OF THE HYBRID COMPOSITE PLATE

\begin{tabular}{|c|c|c|}
\hline Property & Aluminium 2024T3 & Carbon/epoxy \\
\hline $\mathbf{E}_{\mathbf{1}} \mathbf{( M P a )}$ & 72.4 & 145 \\
\hline $\mathbf{E}_{\mathbf{2}} \mathbf{( M P a )}$ & - & 0 \\
\hline $\mathbf{v}_{\mathbf{1 2}}$ & 0.33 & 0.25 \\
\hline $\mathbf{V}_{\mathbf{2 3}}$ & - & 0.25 \\
\hline $\mathbf{G}_{\mathbf{1 2}} \mathbf{( M P a )}$ & 27 & 7 \\
\hline $\left.\mathbf{G}_{\mathbf{1 3}} \mathbf{( M P a}\right)$ & - & 7 \\
\hline $\left.\mathbf{G}_{\mathbf{2 3}} \mathbf{M P a}\right)$ & - & 3.7 \\
\hline
\end{tabular}

In real life applications, cutouts could be of different forms, according to the design needs. Cutout's shape has been assumed primarily to be an elliptical hole at the centre of the plate. However, the effect of different positions for the elliptical cutout on the buckling load is highlighted. These positions are represented by an angle between the major axis of the cutout which is the $\mathrm{x}$-axis by $0^{\circ}, 15^{\circ}, 30^{\circ}, 45^{\circ}, 60^{\circ}, 75^{\circ}$, and $90^{\circ}$. The dimensions of the main diameters of the ellipse are represented by a and $b$. Parameters $a$ and $b$ vary with respect to several chosen ratios. Accordingly, the effect of the circular cutout was also analyzed as a special case when $a=b$. A buckling analysis has been performed for various elliptical and circular cutouts using different models. In addition, particular attention was paid to the number of alternate cross over plies of the laminated plate as well as the plies orientation.

\section{RESULTS AND DISCUSSION}

\section{A. Effect of the Cutout Geometric Ratio on the Buckling Load}

The influence of the ratio $\mathrm{a} / \mathrm{b}$ of the elliptical cutout on the buckling variation parameter is illustrated in Figure 1 for various declinations of the cutout with respect to the $\mathrm{x}$-axis. Three configurations of the hybrid composite material were studied, namely $\left[\mathrm{Al} /(0)_{3} / \mathrm{Al}\right], \quad\left[\mathrm{Al} /(45 /-45)_{3} / \mathrm{Al}\right] \quad$ and $\left[\mathrm{Al} /(90)_{6} / \mathrm{Al}\right]$. In this case, the ellipse major axis is maintained constant $(2 \mathrm{~b}=20 \mathrm{~mm})$ and the minor axis (a) variable.

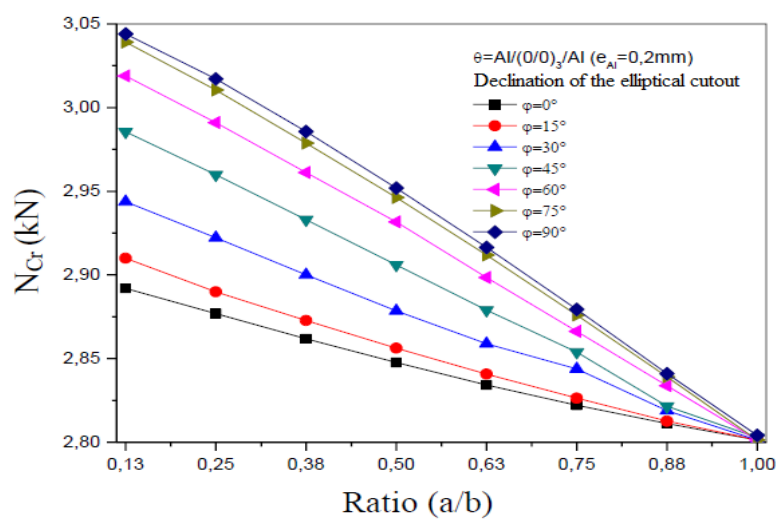

(a)

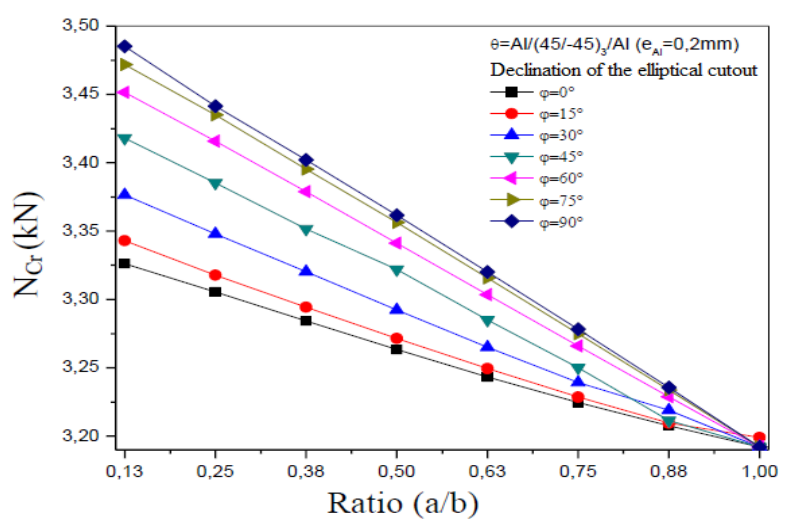

(b)

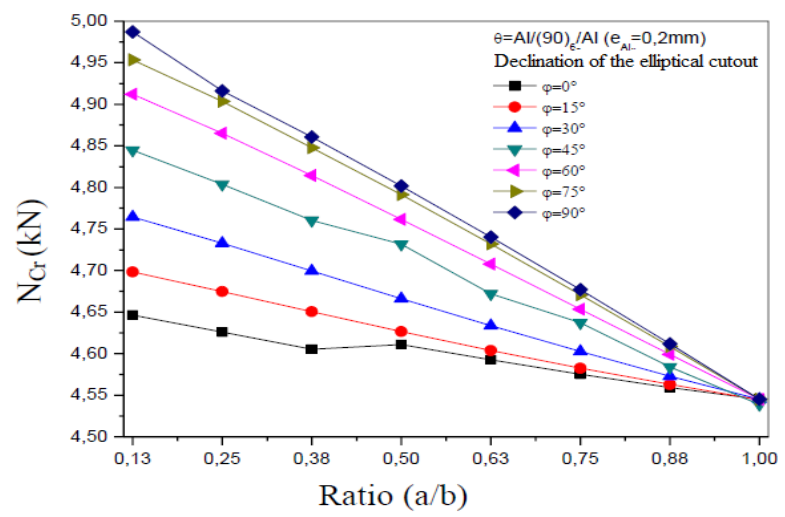

(c)

Fig. 1. Effect of the ratio $a / b$ on the buckling parameter for (a) $\left[\mathrm{Al} /(0)_{3} / \mathrm{Al}\right]$, (b) $\left[\mathrm{Al} /(45 /-45)_{3} / \mathrm{Al}\right]$ and (c) $\left[\mathrm{Al} /(90)_{6} / \mathrm{Al}\right]$ configurations.

Figure 1 shows that the buckling load decreases gradually in a linear manner with regard to the increase of the ratio of the elliptical cutout. This decrease is noticed regardless of the declination angle $\varphi$ of the cutout. The minimum value obtained corresponds to the largest ratio $a / b=1$, i.e. for a circular cutout, and it is almost identical for all cases, while the maximum values are obtained for the lowest ratio $\mathrm{a} / \mathrm{b}$. This means that the 
increase of the cutout radius produces the lowest critical buckling loads in the plates subjected to compression, which makes the bearing capacity of the structure diminish. The slope of the trends increases with the increase of $\varphi$. Therefore, the angle of declination of the elliptical cutout influences the buckling critical factor evolution which in turns influences the buckling critical load. As the cutout major axis tends to be parallel to the applied load, the critical load becomes more important. This indicates that an elliptical cutout whose major axis is parallel to the applied load does not significantly affect the panel's stability. An inverse behavior occurs for the size of the elliptical cutout. In this case, the buckling load importance lessens with the augmentation of the cutout size, in other words, the buckling load decreases with the increase of the cutout size (increase of $a / b$ ) which shows that the resistance of the laminated composite plate will be reduced. The influence of the ratio $a / b$ on the reduction of the buckling critical load for different declinations of the cutout with regard to the $\mathrm{x}$-axis is shown in Figure 2.

The reduction factor is defined by:

$$
N^{*}=1-\frac{N_{w c}}{N_{w t c}}
$$

where $\mathrm{N}_{\mathrm{wc}}$ and $\mathrm{N}_{\mathrm{wtc}}$ are the buckling loads for the hybrid plate with and without the elliptical cutout respectively.

It is to be noted that the maximum reduction in the critical load is marked for the maximum ratio $a / b=1$ regardless of the configuration of the laminated hybrid composite material $\left[\mathrm{Al} /(0)_{3} / \mathrm{Al}\right],\left[\mathrm{Al} /(45 /-45)_{3} / \mathrm{Al}\right]$ and $\left[\mathrm{Al} /(90)_{6} / \mathrm{Al}\right]$. However, the value of the maximum reduction of the critical load is found for the plies orientation $(45 /-45)$ in the configuration $[\mathrm{Al} /(45 /-$ $45)_{3} / \mathrm{Al}$. It is of the order of $10 \%$ in comparison with a plate without an elliptical cutout. The critical load's reduction decreases linearly with the decrease of $\mathrm{a} / \mathrm{b}$. When this equals to $0.125(\mathrm{~b}=8 \mathrm{a})$, the reduction parameter $\mathrm{N}^{*}$ passes from $1.8 \%$ to $7 \%$ when $\varphi=90^{\circ}$ and $\varphi=0^{\circ}$ respectively, therefore the elliptical cutout oriented at $0^{\circ}$, reduces the maximum load four times more than that when it is oriented at $90^{\circ}$. This observation is noticed for all ply orientations cases.

\section{B. Influence of the Cutout Position}

In this part, the buckling load variation as a function of the position of the elliptical cutout center with regard to the applied load is shown in Figure 3. The effect of the declination of the cutout with regard to the $\mathrm{x}$-axis is highlighted for the three configurations of the hybrid laminated composite material $\left.\mathrm{Al} /(0)_{6} / \mathrm{Al}\right],\left[\mathrm{Al} /(45 /-45)_{3} / \mathrm{Al}\right]$ and $\left[\mathrm{Al} /(90)_{6} / \mathrm{Al}\right]$. The size of the elliptical cutout is considered constant; ie. $a / b=1 / 3$. It should be noticed that regardless of the position (h) of the cutout, there are two peaks indicating the critical buckling stress in the range $20-30 \mathrm{~mm}$ and $70-80 \mathrm{~mm}$, that is to say in the bottom and top ends respectively close to the fixed boundary and applied load, and a peak of minimum critical stress obtained in the middle of the plate $(\mathrm{h}=50 \mathrm{~mm})$. It is clear that the presence of a cutout in the middle of the plate reduces the bearing capacity of the hybrid composite plate. It is noticeable that the curves are sinusoidal and symmetrical about the plate axis. Also, it is worth mentioning that the increase of the angle of declination $\varphi$ of the cutout leads to the increase of the critical buckling load where the largest values are obtained for $\varphi=90^{\circ}$. Better plate resistance is attained when the cutout minor axis is perpendicular to the applied load compared to the case where the cutout minor axis is parallel to the applied load $\left(\varphi=0^{\circ}\right)$. The extremum values have the tendency to be amplified when the ply orientation angle $\theta$ tends toward $90^{\circ}$. For a clear illustration of this phenomenon, the reduction parameter of the buckling load as a function of the height $\mathrm{h}$ is drawn in Figure 4 where it could be noticed that the reduction trends of the critical load are reversed in comparison with those shown in Figure 3.

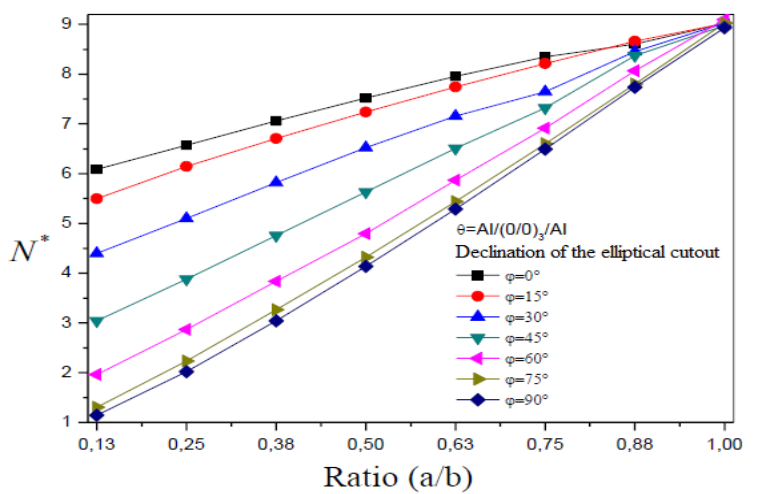

(a)

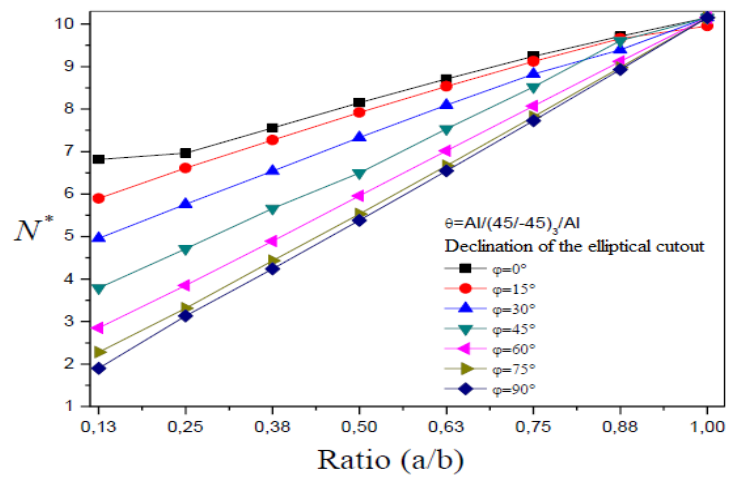

(b)

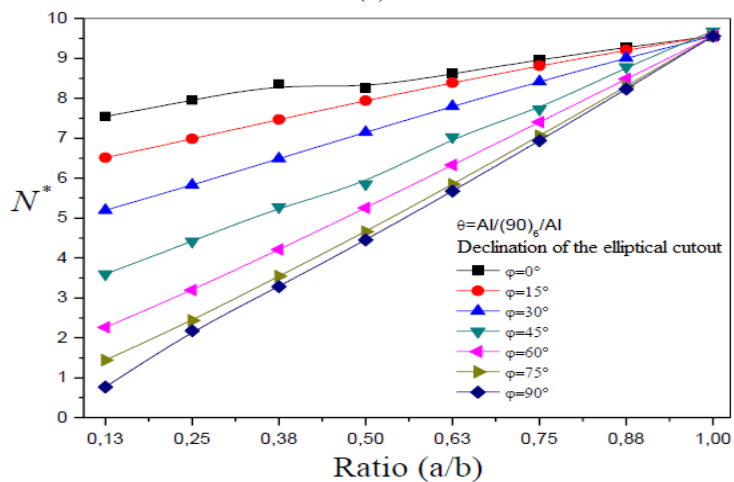

(c)

Fig. 2. Effet of the ratio $\mathrm{a} / \mathrm{b}$ on the critical buckling load reduction for (a) $\left[\mathrm{Al} /(0)_{3} / \mathrm{Al}\right]$, (b) $\left[\mathrm{Al} /(45 /-45)_{3} / \mathrm{Al}\right]$ and (c) $\left[\mathrm{Al} /(90)_{6} / \mathrm{Al}\right]$ configurations.

The maximum reduction of the buckling critical load is important when the elliptical cutout is located in the middle of 
the plate. It reaches $7 \%, 7.5 \%$ and $8.5 \%$ respectively for $\theta$ values of $0 \mathrm{o}, 45 \mathrm{oand} 90 \mathrm{o}$ when the cutout is oriented at $0^{\circ}$ $(\varphi=0 \mathrm{o})$. Minimum reduction is attained for the orientation of the plies at $90 \mathrm{o}$. The smallest reductions of the critical load occur when the cutout is oriented at $90 \mathrm{o}(\varphi=90 \mathrm{o})$ of the order of $2 \%, 3.5 \%$ and $2.5 \%$ regardless of the hybrid plate configuration.

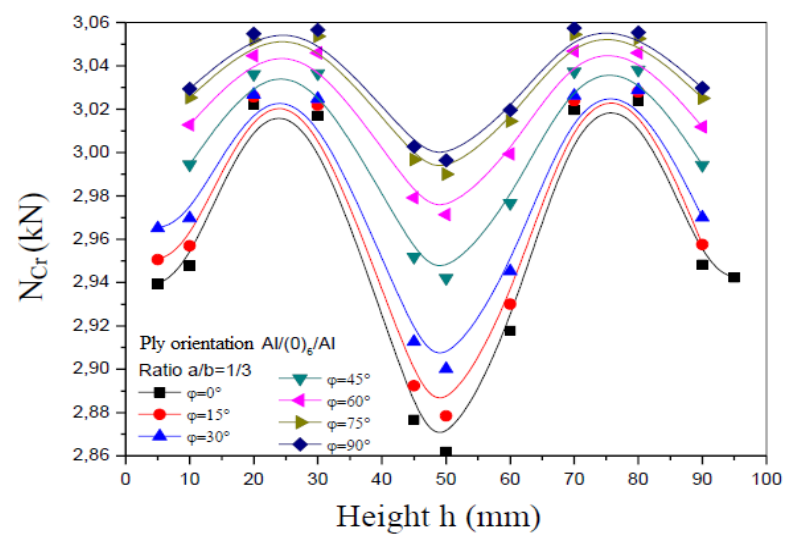

(a)

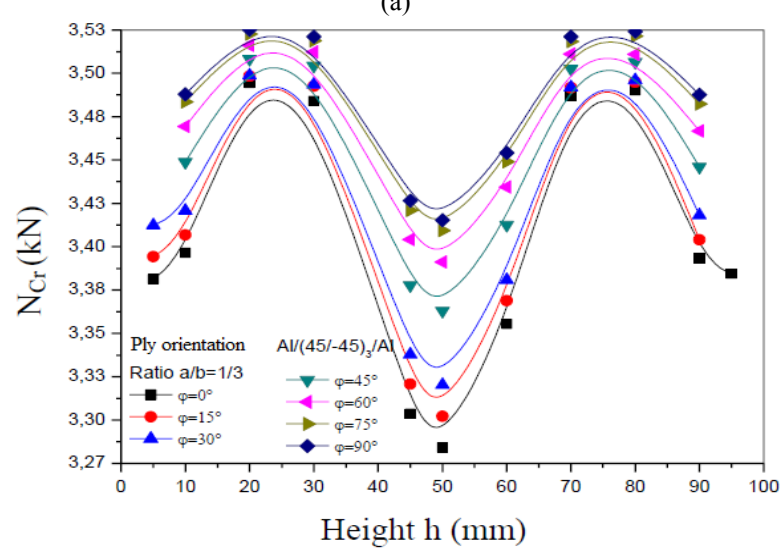

(b)

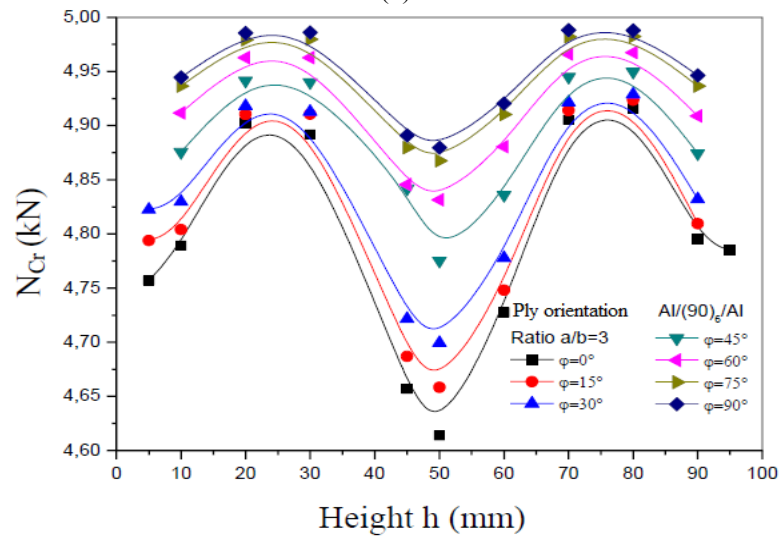

(c)

Fig. 3. Effect of the height $\mathrm{h}$ on the buckling parameter for (a) $\left[\mathrm{Al} /(0)_{6} / \mathrm{Al}\right]$, (b) $\left[\mathrm{Al} /(45 /-45)_{3} / \mathrm{Al}\right]$ and (c) $\left[\mathrm{Al} /(90)_{6} / \mathrm{Al}\right]$ configurations.

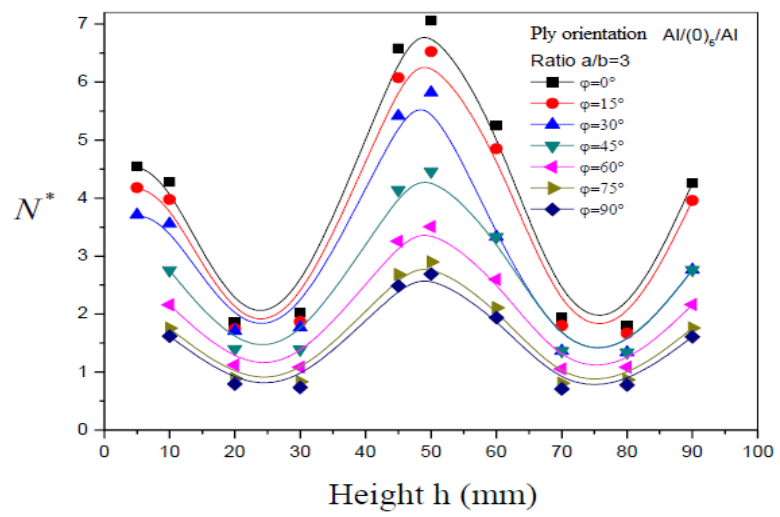

(a)

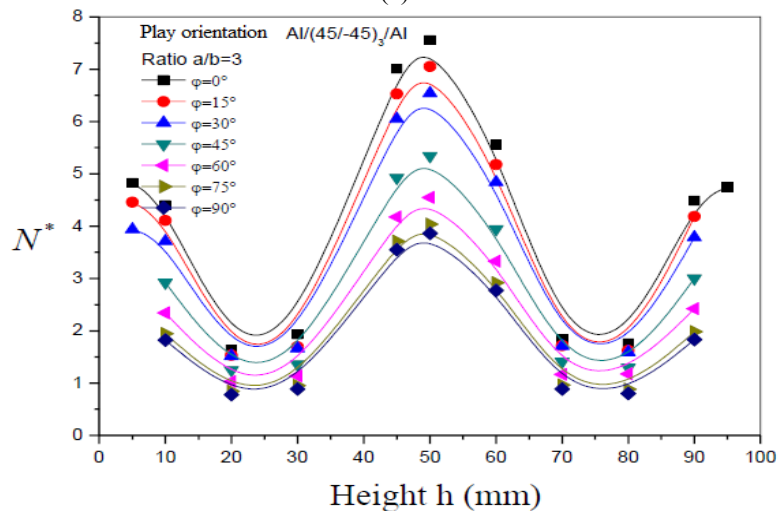

(b)

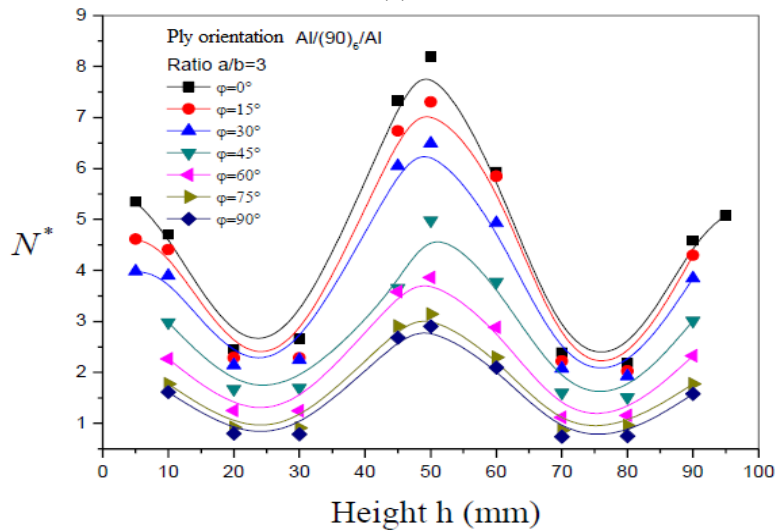

(c)

Fig. 4. Effect of the height $\mathrm{h}$ on the buckling load reduction for (a) $\left[\mathrm{Al} /(0)_{6} / \mathrm{Al}\right]$, (b) $\left[\mathrm{Al} /(45 /-45)_{3} / \mathrm{Al}\right]$ and (c) $\left[\mathrm{Al} /(90)_{6} / \mathrm{Al}\right]$ configurations.

\section{Influence of the Rigidity Ratio}

The effects of the Young modulus ratios are also studied for different orientations of the laminated structure with and without the presence of the elliptical cutout. Three cases of cutout position $\varphi$ are studied: $0^{\circ}, 45^{\circ}$ and $90^{\circ}$. As shown in Figure 5, the buckling load increases exponentially with the importance of the ply orientations when the Young modulus ratios are less than 0.4. Beyond this value, the buckling load trends tend to be more and more parabolic. In other words, the maximum buckling load will be almost identical for $\theta=0^{\circ}$ and 
$\theta=90^{\circ}$ for a ratio $E_{2} / E_{1}=1$, and the minimum load is obtained for $\theta=45^{\circ}$.

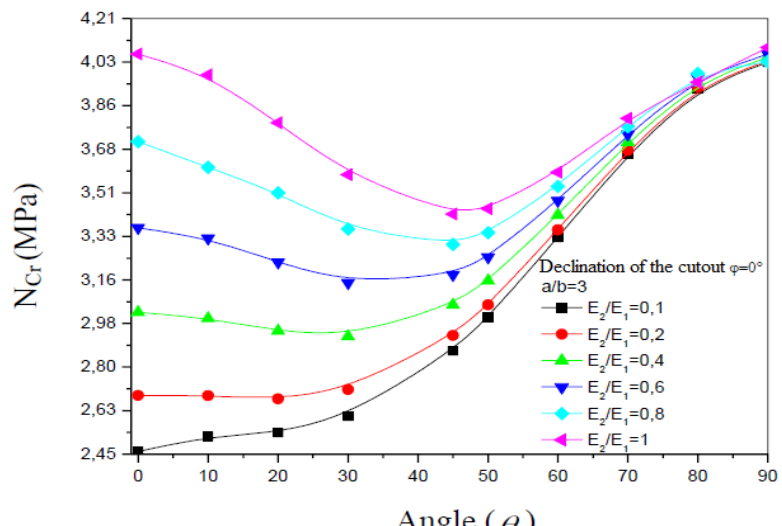

(a)

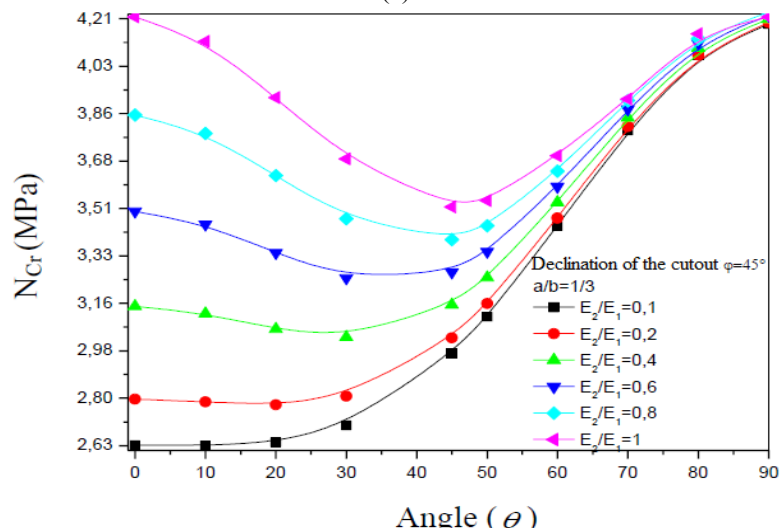

(b)

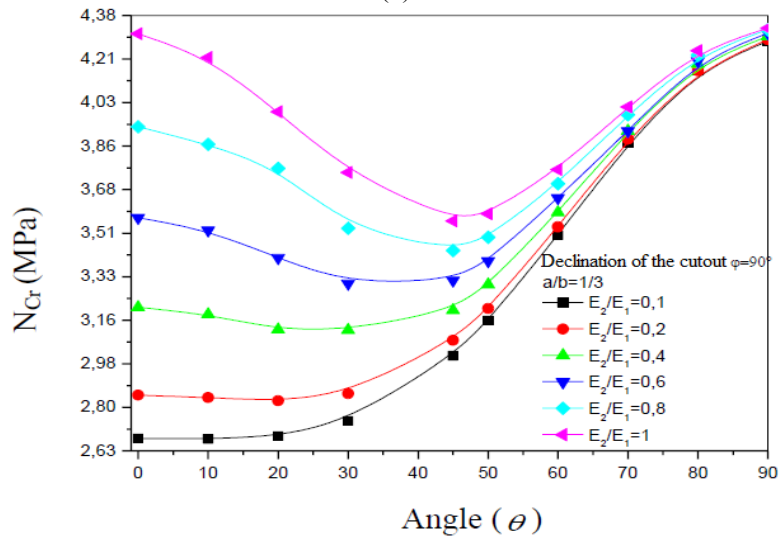

(c)

Fig. 5. Buckling load for modulus ratio versus ply orientation angles for $\varphi$ : (a) $0^{\circ}$, (b) $45^{\circ}$ and (c) $90^{\circ}$.

It is worth mentioning that the maximum value is obtained for $\theta=90^{\circ}$ regardless of the cutout position. When the orientation angle of the elliptical cutout is $\varphi=0^{\circ}$, the values of the critical buckling load are generally lower compared to the other orientations, which shows that in that case, the cutout presents a greater risk of damage. In the absence of a cutout, the hybrid laminated composite plate is more resistant. When the two properties $E_{1}$ and $E_{2}$ are nearly equal, the critical load increases on both sides of the ply orientation angle $\theta=45^{\circ}$. The critical load decreases with the decreasing value of the ratio $E_{2} / E_{1}$. Emphasizing on the effect of the ratio of the Young's modulus on the evolution of the buckling parameter, the amplification $\mathrm{N}^{*}$ as a function of the fiber orientations for different ratios of rigidity is plotted and shown in Figure 6.

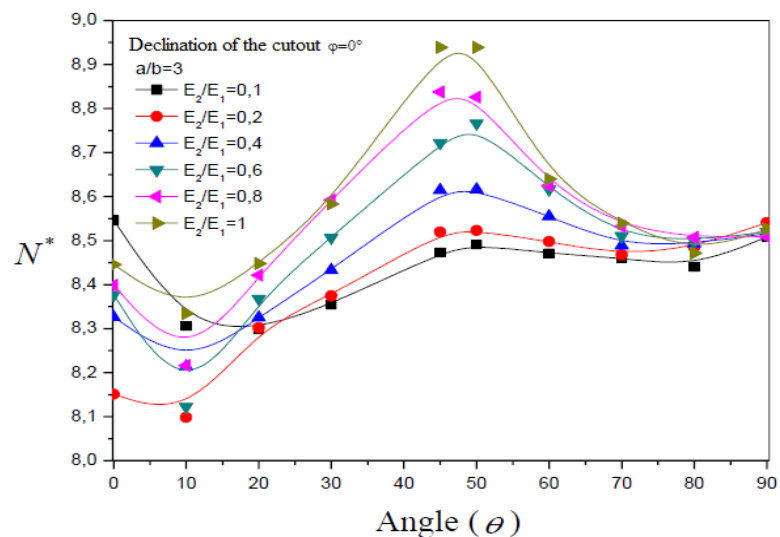

(a)

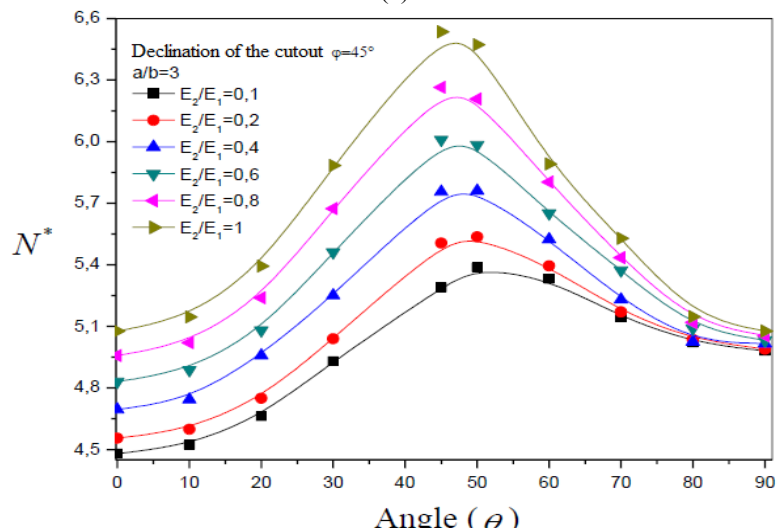

(b)

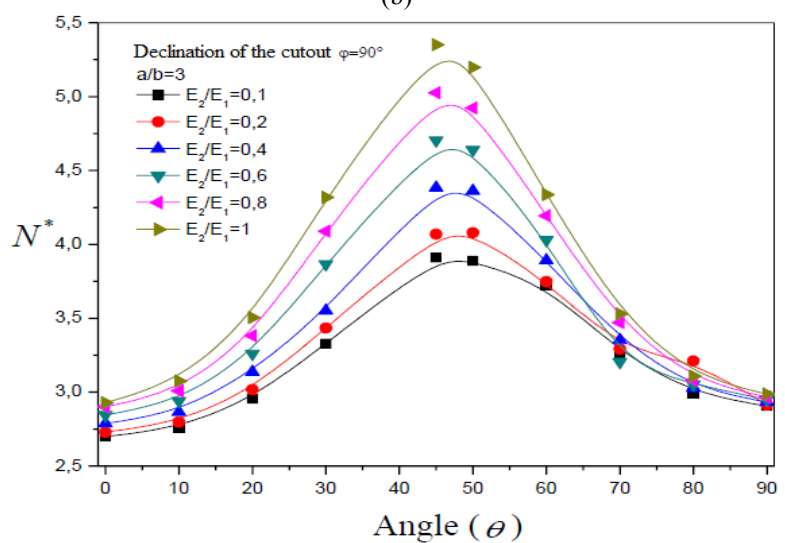

(c)

Fig. 6. Effect of the ratio $\mathrm{E}_{2} / \mathrm{E}_{1}$ on the buckling amplification parameter for $\varphi$ : (a) $0^{\circ}$, (b) $45^{\circ}$ and (c) $90^{\circ}$.

It should be noted that for $E_{2} / E_{1}=1$, all the peaks are attained when $\theta=45^{\circ}$. Regardless of the declination of the 
elliptical cutout, the maximum reduction of the critical buckling stress is obtained when $\mathrm{E}_{2} / \mathrm{E}_{1}=1$. Thus, the maximum reduction is obtained when the cutout is oriented at $0^{\circ}$ while it is minimum when it is at $90^{\circ}$. This shows that the cutout at $0^{\circ}$ reduces the structure capacity more. The maximum reduction of the plate bearing capacity is of the order of $8.5 \%, 5 \%$ and $3 \%$ respectively for the cutout orientations $0^{\circ}, 45^{\circ}$ and $90^{\circ}$ of $\varphi$.

\section{CONCLUSION}

In this study, the buckling response of a hybrid composite square plate in the presence of an elliptical cutout was investigated. The effects of the orientation angle of the elliptical cutout, the cutout geometry, the orientation of the plies of the composite material, the position of the elliptical cutout and the rigidity ratio of the material on the variation of the buckling load were highlighted leading to the following findings:

- The buckling load increased exponentially with regard to the increase of the orientation angle of the composite material plies. This increase was much faster and more important for $\theta \geq 45^{\circ}$.

- For all the laminated hybrid composite configurations used, the more the size $a / b$ of the cutout is important the less is the buckling load.

- The critical load reduction is found to decrease linearly with decreasing geometric ratios $a / b$. When $b=8 a$, the reduction factor $\mathrm{N}^{*}$ increased from $1.8 \%$ to $7 \%$ respectively for $\varphi=90^{\circ}$ and $\varphi=0^{\circ}$ regardless of the ply orientations. When the elliptical cutout is declined by $0^{\circ}$, it reduces the maximum load four times more than when it is declined by $90^{\circ}$.

- Regardless of the hybrid plate configuration, the maximum reduction of the critical buckling load is important when the elliptical cutout is located in the middle of the plate. It reaches $7 \%, 7.5 \%$ and $8.5 \%$ respectively for $\theta=0^{\circ}, 45^{\circ}$ and $90^{\circ}$ when the cutout is oriented at $\varphi=0^{\circ}$.

- When the two properties $E_{1}$ and $E_{2}$ are nearly equal, the critical load increases on both sides of the ply orientation angle $\theta=45^{\circ}$, while the critical load decreases with decreasing values of the ratio $\mathrm{E}_{2} / \mathrm{E}_{1}$.

\section{ACKNOWLEDGMENT}

This research was funded by the Deanship of Scientific Research at the University of Hail, Saudi Arabia, under the contract (E-2-CE). Authors would like to express their gratitude to the Deanship of Scientific Research and to the College of Engineering at the University of Hail for providing all required facilitations.

\section{REFERENCES}

[1] H. Allahbakhsh, A. Dadrasi, "Buckling Analysis of Laminated Composite Panel with Elliptical Cutout Subject to Axial Compression", Modelling and Simulation in Engineering, Vol. 2012, Article ID171953, pp. 1-10, 2012

[2] M. Aydin Komur, F. Sen, A. Atas, N. Arslan, "Buckling analysis of laminated composite plates with an elliptical/circular cutout using
FEM", Advances in Engineering Software, Vol. 41, No. 2, pp. 161-164, 2010

[3] M. D. Rhodes, M. M. Mikulas, P. E. McGowan, "Effects of orthotropy and width on the compression strength of graphite-epoxy panels with holes”, AIAA Journal, Vol. 22, No. 9, pp. 1283-1292, 1984

[4] M. P. Nemeth, "Buckling behavior of compression-loaded symmetrically laminated angle-ply plates with holes", AIAA Journal, Vol. 26, No. 3, pp. 330-336, 1988

[5] P. R. Reddy, T. Harish, "Buckling Analysis of Orthotropic Laminated Composite Plate With Rectangular Cut-Outs by Using FEA", International Journal of Emerging Technologies in Computational and Applied Sciences, Vol. 10, No. 1, pp. 75-81, 2014

[6] A. W. Leissa, Buckling of laminated composite plates and shell panels, AFWAL-TR-85-3069, Flight Dynamics Laboratory, Air Force Wright Aeronautical Laboratories, Wright-Patterson Air Force Base, Ohio, 1985

[7] A. Muc, "Optimal fibre orientation for simply-supported angle-ply plates under biaxial compression", Composite Structures, Vol. 9, No. 2, pp. 161-172, 1988

[8] H. T. Hu, B. H. Lin, "Buckling optimization of symmetrically laminated rectangular plates with various geometry and end conditions", Composites Science and Technology, Vol. 55, No. 3, pp. 277-285, 1995

[9] S. Vellaichamy, B. G. Prakash, S. Brun, "Optimum design of cutouts in laminated composite structures", Computers and Structures, Vol. 37, No. 3, pp. 241-246, 1990

[10] B. O. Baba, "Buckling behavior of laminated composite plates Journal of Reinforced Plastics and Composites, Vol. 26, No. 16, pp. 1637-1655, 2007

[11] M. Zor, F. Sen, M. Evren Toygar, "An investigation of square delamination effects on the buckling behavior of laminated composite plates with a square hole by using three-dimensional FEM analysis", Journal of Reinforced Plastics and Composites, Vol. 24, No. 11, pp. 1119-1130, 2005

[12] I. Shufrin, O. Rabinovitch, M. Eisenberger, "Buckling of laminated plates with general boundary conditions under combined compression, tension, and shear-A semi-analytical solution", Thin-Wall Structures, Vol. 46, No. 7-9, pp. 925-938, 2008

[13] B. O. Baba, A. Baltaci, "Buckling characteristics of symmetrically and antisymmetrically laminated composite plates with central cutout", Applied Composite Materials, Vol. 14, No. 4, pp. 265-276, 2007

[14] S. A. M. Ghannadpour, A. Najafi, B. Mohammadi, "On the buckling behaviour of cross-ply laminated composite plates due to circular/elliptical cutouts", Composite Structures, Vol. 75, No. 1-4, pp. 3-6, 2006

[15] N. Hamani, D. Ouinas, N. Benderdouche, M. Sahnoun, "Buckling analyses of the antisymetrical composite laminate plate with a crack from circular notch", Advanced Materials Research, Vol. 365, pp. 56-61, 2012

[16] D. Ouinas, B. Achour, "Buckling analysis of laminated composite plates $[(\theta /-\theta)]$ containing an elliptical notch", Composites Part B: Engineering, Vol. 55, pp. 557-579, 2013 